really grasped the all-important stability problem, or that the necessity of carefully studying the small oscillations of gliders, both stable and unstable, has been appreciated. It seems probable that a great many constructors of would-be flying machines do not even know what is meant by a moment of inertia, yet both theory and experiment tend to show that the stability of a machine depends partly on its moment of inertia being neither too large nor too small.

The models exhibited are of various sizes, and adapted for propulsion through the air by means of twisted elastics, like the familiar toys; they are, however, of various dimensions, say from about 3 feet to 6 feet. The trials which were made at the Alexandra Palace on Monday thus involved none of the dangers attendant on experiments with man-carrying machines. It is to be hoped that some means were taken to record the actual motions of the models while in the air. Such a record, if made in a way that would enable the positions and the velocities of the models to be plotted at every instant of the motion, could be made to furnish material the study of which will greatly advance our knowledge of the flight problem. From what I learnt at the exhibition, it appeared that this matter had not received much, if any, attention, but I was given to understand that two kinematographs would be employed to obtain the necessary records. The necessity for two is obvious, and I can only hope that the requisite measurements of base line and angles were also attended to.

In the following remarks I shall assume the result that a machine supported on aëroplanes has two kinds of longitudinal oscillations of different period, either of which may give rise to instability. This is not generally known, but it is desirable to analyse the models even in the light of ideas which are to some extent anticipatory. The rough notes taken are far from exhaustive, but they summarise a few points regarding some of the more conspicuous exhibits.

Ezio Tani shows a most elegant and beautifully constructed mechanism in connection with the motor; the arrangement of wings does not look very practicable.

Balston and Cochrane both exhibit propellers, \&c. of corrugated aluminium.

The avroplane looks a fairly practicable model. The arrangement of two sets of planes tandem fashion appears suited for stability, at any rate so far as the short oscillation is concerned, but a great deal depends on whether the planes are parallel or inclined at a slight angle. On the other hand, the increased moment of inertia caused by the projecting framework and the considerable distance between the front and hind surfaces may give trouble with the long-period oscillation.

The Drexler model seems to go to the other extreme, and suggests that the shortness of base may lead to trouble with the quick-period oscillation. Here the planes are superposed, not arranged tandem.

Weiss's albatross is really a model of a bird with curved wings. How far this imitation of the shape of bird's wings conduces to stability cannot be completely studied without further experimental data than are at our disposal. The model looks as if it would glide well for a short distance, but without a very careful system of recording, short flights teach us but little.

Montford Kay shows a model of great length with propeller placed in the middle of a number of long parallel aëroplanes. The arrangement seems illcalculated for obtaining much lifting force from the air.

Piffard shows a reasonable form of model with two pairs of superposed aërocurves, one behind the other. As arranged at the exhibition, the combination looked as if it would be unstable for moderate velocities, but a slight change in the inclination of the aêrocurves might make all the difference.

T. W. K. Clark shows the most genuine attempt to cope with the problem of stability, he having followed the lines laid down by Chanute in the matter of flexible framework. From what I could gather, however, the necessary movements for balancing were not arranged to take effect automatically, but the machine was a small-sized model of a type intended to be balanced and controlled by the dexterity of an aëronaut.

It would be impossible from these rough observations to draw any very definite conclusions about the probable results of the competition, but it may be apposite to remark in conclusion that failures may teach quite as much as successes if only they are properly studied.

G. H. BRYAN.

\section{THE STUDY OF EARTHQUAKES.}

THE Imperial Earthquake Investigation Committee of Japan has supplemented its wellknown Publications by a bulletin, issued with the object of securing a quick publication of short notes and preliminary reports on seismological subjects. The series opens with a very interesting number; there are papers on the determination of the time of origin of a distant earthquake, on the methods of calculating the velocities of earthquake propagation, on the Tokyo records of the Calabrian earthquake, and, most interesting of all, a discussion of the cause of the San Francisco earthquake, by Prof. Omori, who describes the great fault-fissure, referred to in NAture of June 2r, Igo6 (vol. lxxiv.), and notices that near Pt. Arena and at some other places it did not show at the surface as a simple fault-fissure, but as a zone of distortion crossed by parallel shearcracks, from the direction of which he concludes that, besides the relative displacement of the two sides of the fault zone, there was a general compression of the country from north to south. This displacement was no mere surface phenomenon, as it appeared in the tunnel near Wright station, some forty miles S.S.E. of San Francisco, at a depth of some 700 feet from the surface. From the direction of overthrow of objects, Prof. Omori concludes that the whole of the country along the fault has been displaced towards the N.N.W., but the west side more than the east.

In Austria the collection of earthquake statistics has been taken over from a committee of the Imperial Academy of Sciences by a newly extended Government Institute of Meteorology and Geodynamics. The first of the seismological publications of this institute is a catalogue of the earthquakes of the Austrian Empire in I904, which are detailed province by province, with the addition of a general summary. A catalogue of this sort is as important and useful as a collection of meteorological tables; it is little more interesting to read, but, if not pleasant reading in itself, this little pamphlet suggests some interesting if not very comforting considerations. The science of seismology is essentially an English one; it is to Englishmen, and practically to two of them, that most of its fundamental concepts owe their origin; the ideas, which give vitality, and the terms which are in universal use, have almost all been born in this country, yet England remains without any permanent or official organisation for the collection of earthquake information, while one country after another is establishing a special service for this purpose. Nor can the neglect be excused by 
the plea that the British Government is not concerned in the subject as are those of Japan and Italy, for, if we are fortunately exempt from the visitation of seriously destructive earthquakes, this is not true of our possessions; moreover, as one of the principal suppliers of the materials which will be used in the building of earthquake-proof construction, we have a distinct national interest in earthquakes. In England, too, has been formed the most valuable organisation which exists for the study of those broader aspects of seismology in which the cooperation of widely separated observers is necessary; at more than fifty stations, scattered over the surface of the globe, instruments capable of recording distant earthquakes have been set up, and all report to one central station, where an abstract of their records is periodically published, but this organisation, which we owe to Prof. Milne, is entirely dependent on the energy and initiative of one man, it has no official status or permanent foundation, which will ensure its permanence or extension.

Meanwhile, Germany has been to the fore and instituted an International Seismological Association, which, not content with the holding of periodical meetings, on the model of the international congresses, has established a central bureau at Strassburg, where it aims at concentrating the study of earthquakes and the collection of seismological data. So far its activities have been largely devoted to the preparation of a catalogue of the earthquakes of the whole world, necessarily too incomplete to be of great scientific value, and to the collection, for the purpose of publication, of the seismograms of the Valparaiso earthquake, which, as has been shown in our pages, do not exist in that complete form, uncomplicated by the effect of other disturbances, which is necessary for scientific study. As aids to the advancement of science these count for very little, as advertisements they are invaluable; and in saying this we insinuate nothing against the founders of the International Seismological Association, we may acquit them of any commercial intention, we recognise the great services which its promoter has rendered to science, but the facts remain that, where the information is there will people go for advice, and where they go for advice there too will they obtain their materials: and so we are in a fair way to a repetition of the lesson of the Jena glass.

\section{INDIAN ORCHIDS. 1}

$\mathrm{O}^{\mathrm{N}}$ $\mathrm{NE}$ of the largest and most generally distributed of the natural families of Indian plants, the Orchids form at the same time a group in which considerable interest is taken by European residents in our eastern dependency. No order affords more satisfactory data where questions as to the distribution of species have to be dealt with or points connected with endemism require illustration. The value of such data increases as the records for particular areas approach completeness. In order that the records for at least one area might be made as nearly as possible exhaustive, Sir G. King planned, and with the help of Mr. R. Pantling, who made the necessary drawings, carried out a scheme for the description and delineation from fresh material of every orchid known to occur in Sikkim. The results were published in "Orchids of the SikkimHimalaya," which forms the eighth volume of the Calcutta Garden Annals.

1 "The Orchids of the North.Western Himalaya." By J. F. Duthie. Annals of the Reyal Poranic Farden. Calcutta, vol. ix. part ii. Pp. iitizi with $5^{8}$ plates. (Calcutta: Bengal Secretar at Press, rgo6)

NO. I955, vOL. 75$]$
The present work is, as Mr. Duthie explains, to be regarded as a supplement to that on the orchids of Sikkim. The area dealt with, which comprises the whole of the Himalaya to the west of Nepal, between $70^{\circ} 30^{\prime}$ and $80^{\circ} 40^{\prime}$ E., is no doubt much more extensive than the area investigated in the previous volume, which comprises only that part of the Himalaya which lies between Nepal and Bhutan, from $88^{\circ}$ to $89^{\circ} \mathrm{E}$. But though this be the case, the number of species to be dealt with is much smaller; only 173 orchids are known to occur in the whole north-western Himalaya, as compared with 449 in Sikkim alone, and of these 105 are common to both areas. The same thoroughness has, however, characterised the search for material, and the same care marks the description of the species, though some may regret that the scope of the work has not allowed of fuller criticism in certain places of the work of previous writers. The author has been especially fortunate in having at his disposal the services of a competent artist, Mr. Hormusji Deboo, who has prepared fifty-eight highly satisfactory figures of those species that are to be found in the north-western Himalava, but that do not occur in Sikkim.

Apart from its value to systematic botanists and students of phytogeography, the work will be welcomed by residents in the hill stations of the north-west Himalaya as the previous volume has been by residents in Sikkim, who in their study of the orchids they meet with find themselves, particularly at first, unable fully to appreciate the characters and relationships of the species before them when they have to rely for information on technical descriptions, however excellent, that are unaccompanied by illustrations. Regret will perhaps be felt that so few plates have been given. It is true that figures of the other 105 species are to be found in the work on the orchids of Sikkini, and it will be realised that the editor of the Annals must have felt himself precluded from incurring the expenditure involved in figuring the same species a second time. Still, the fact remains that the figures in the work on the Sikkim orchids, though good, fail to come up to the standard of the work of a trained draughtsman.

The author may be congratulated on the production of a memoir which sustains the character imparted to these Annals by the distinguished botanist who founded the series. The two ideals of scientific accuracy and practical utility, aimed at in previous volumes, have been kept steadily in view, and the enlightened liberality of the Government of Bengal, which has rendered their publication possible, will be as gratefully recognised by botanical workers crenerally as it is by the editor of the Annals in the dedication of the volume before us.

\section{A RECENT ADVANCE IN THE KNOWLEDGE OF CANCER.}

A COMPLETE presentation of the doctrine of the gametoid nature of malignant growths and of the grounds upon which that doctrine rests is contained in the first report on the cytological investigation of cancer, recently published. ${ }^{i}$ The papers dealing with this subject have appeared in various publications, commencing with the original communication to the Royal Society by Farmer, Moore, and Walker in 1903, and they are here collected together and pre-

1 University of Liverpool and Royal Infirmarv Cancer Research Laboratories (Mrs. Sutton Timmis Memorial Fund). First Report on the Cy'ological Inves'igalion of Cancer. 1905. By J. E. S. Monre and C. E. Walker. Pn. 87. (Liverpnol: Publish?d for the Liverposl Cancer Research Committee by the Priory Publishing Co., n.d.) 